\title{
Influence Analysis of Mine Flooding from the Environmental Standpoint: Surface Protection
}

\author{
Marek Wesołowski, Ryszard Mielimąka, Rafał Jendruś*, Marcin Popczyk \\ Silesian University of Technology, Faculty of Mining and Geology, \\ Akademicka 2A, 44-100 Gliwice, Poland
}

Received: 30 May 2017

Accepted: 27 July 2017

\begin{abstract}
Water that floods the mining complexes is drained on a constant basis when a mine is still active, but the situation changes the moment the mine is closed. This article presents the influence that flooding of mine workings has on a surface of a mining area using computer simulation. The evaluation of potential changes to the surface and scale of this phenomenon has been done using as examples the exploitation of mine deposit layers 702, 705, and 718 of the old Gliwice and Pstrowski mines. The performed numerical simulation showed that using numerical modeling of rock mass demonstrates the possibility of predicting uplifting of the surface caused by flooding of underground workings. Maximum designated value of surface uplifting amounts to around $34 \mathrm{~mm} / \mathrm{m}$. This value is relatively small and does not exceed $2 \%$ of subsidence caused by previous mining activity.
\end{abstract}

Keywords: partial exploitation, calculation model, terrain deformations, surface protection

\section{Introduction}

Water that floods the mining complexes is drained on a constant basis when a mine is still active, but the situation changes the moment the mine is closed. Mines that are closed usually flood as a result of stopping the drainage from existing and liquidated mine workings.

Closing a mine by flooding may lead to unexpected occurrences related to secondary movements of rock mass and surface caused by that flooding. Quakes may also occur, despite the cancelation of mining exploitation in the area covered by the influence of old mining activity.

Research shows that during the flooding of a mine a relative uplifting of a surface can often be observed.

*e-mail: rafal.jendrus@polsl.pl
It should be noted that the uplifting is relatively small, considering the initial subsidence of the surface caused by the mining of a deposit. This phenomenon was observed in Germany many times with registered measurements. So far, geodetic surveys have proven that such uplifts do

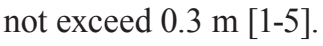

Small uplifts of terrain surface, especially in built-up areas, may be a result of mining damage. For this reason, broader analysis will be needed, which will show the causes and effects of flooding of closed mines and allow for the development of an effective method for predicting uplifts of a mining area.

This article presents the influence that flooding mine workings has on the surface of a mining area using computer simulation. The evaluation of potential changes to the surface and scale of this phenomenon has been done using as examples the exploitation of mine deposit layers 702,705 , and 718 of the old Gliwice and Pstrowski mines. 


\section{Materials and Methods}

\section{Computational Method}

The Fast Lagrangian Analysis of Continua (FLAC) software from Itasca Consulting Group has been used for the purpose of numerical modeling in this study. The software was developed by Peter Cundalla and his co-workers from the University of Minnesota and Itasca Consulting Group in 1986, and it is based on finite difference method [6].

The software is used for building numerical models of rock mass and simulating the behavior of soil and rock media, which are subjected to plastic flow and cracking after reaching the plasticity point or strength limit. The software is especially recommended for solving issues of rock engineering. It is used for evaluating the behavior of rock mass in working mine areas as well as modeling discontinuities in rock media and simulating the behavior of rock massive and buildings with dynamic forces.

Plasticity of the rock mass in the model is taken into consideration by presuming that in the area restricted by specific planes, the rock mass behaves in linear and elastic fashion and it is plastic beyond that area. Plasticity in FLAC software is based on the presumption that a total increase of deformation is divided between elastic deformation increase and plastic deformation increase.

For the purposes of numerical procedure, the increase of deformation, which is determined by Hooke's Law, is calculated first, and then the stress is calculated based on the value of deformations. If stress values exceed the boundary plane (which defines the specified strength criteria) then it is assumed that plastic deformation occurs. In such a case, only elastic deformations take part in calculating further stress increase.

In the finite difference method each derivative in a system of equations is described by algebraic expression presented as set of variables (stress and deformations). These variables are registered in discrete points of the model but they are not defined in the range of each zone of differential grid.

The utilization of finite difference method leads to the transformation of a differential equations system in an algebraic equations system. These systems change after each calculation step. FLAC software uses an explicit method of consecutive steps to solve the differential equation system. The explicit method is based on using small time increases, which are selected in such a way that during each calculation step there is no displacement between two adjacent zones. Despite using small calculation steps it is a very effective method that does not require high computing power.

The most of the software based on finite elements utilizes an implicit method of global rigidity matrix of individual elements. This process requires mutual "communication" between each element of the grid. Thus, achieving equilibrium of the studied system requires a higher number of iterations and in consequence higher computing power.
The feature of FLAC method of finite difference is the fact that it does not require preparation of global rigidity matrix. Updating the coordinates of the finite difference grid's nodes takes place with every calculation step. According to Lagrange's calculation scheme, the increases of displacements are added to the coordinate's grid each time, which is deformed along with the model, compared to Euler's formula, where displacements and deformations of the model take place in relation to the stationary grid.

Therefore, solving the equations of individual nodes of the grid designates speed of displacement, which is the basis for calculating deformation increases. Despite the fact that the software dynamically solves movement equations, the main solution of the problem is achieved the moment the model reaches equilibrium or the unbalanced strength reaches an acceptable value.

\section{Geological and Mining Conditions}

Rock mass consists of Quaternary, Tertiary, and Triassic rocks, which are the overburden and Coal Measuring rocks. The latter are the coal-bearing rocks. Quarternary is $20 \mathrm{~m}$ thick on average and is present in the whole mining area. The maximum thickness of $60 \mathrm{~m}$ is reached in the Bytomka River Valley. It mostly consists of clays, silts, and sands of various grain size as well as gravel. Tertiary is only present in the form of local patches, $5-40 \mathrm{~m}$ thick. It mostly consists of Miocene clays. Carboniferous layers that form the deposit are represented by rudzkie, siodłowe, porębskie, jaklowieckie, and gruszowskie layers. Layers 702, 705, and 718 were directly mined in the studied area as outlined below:

- Seam 702: four faces were exploited to a height of 0.8-1.0 m; the faces were exploited in 1962-66 at a depth of 130-240 $\mathrm{m}$ using the longwall system with controlled roof fall and backfilling strips mined out from the roof of the layer.

- Seam 705: seven faces were exploited to a height of $0.8-1.0 \mathrm{~m}$; the faces were exploited in 1963-71 at a depth of 130-330 $\mathrm{m}$ using the longwall system with controlled roof fall and backfilling strips mined out from the roof of the layer.

- Seam 718: 12 faces were exploited to a height of 0.7-1.2 $\mathrm{m}$; the faces were exploited 1961-72 at a depth of 130-430 $\mathrm{m}$ using the longwall system with controlled roof fall and backfilling strips mined out from the roof of the layer

\section{Rockmass Model}

A flat numerical model of size 2,400 x 1,000 m was built (Fig. 1) to make a computer simulation of the rock mass movement and the influence of goaf flooding on surface deformations. This model presents the most significant structural elements of the rock mass in the studied mining area. At a depth of 150-400 m, four layers have been modeled with the following numbers: 702, 705, 716, and 718. Layers 702, 705, and 718 were subjected to 


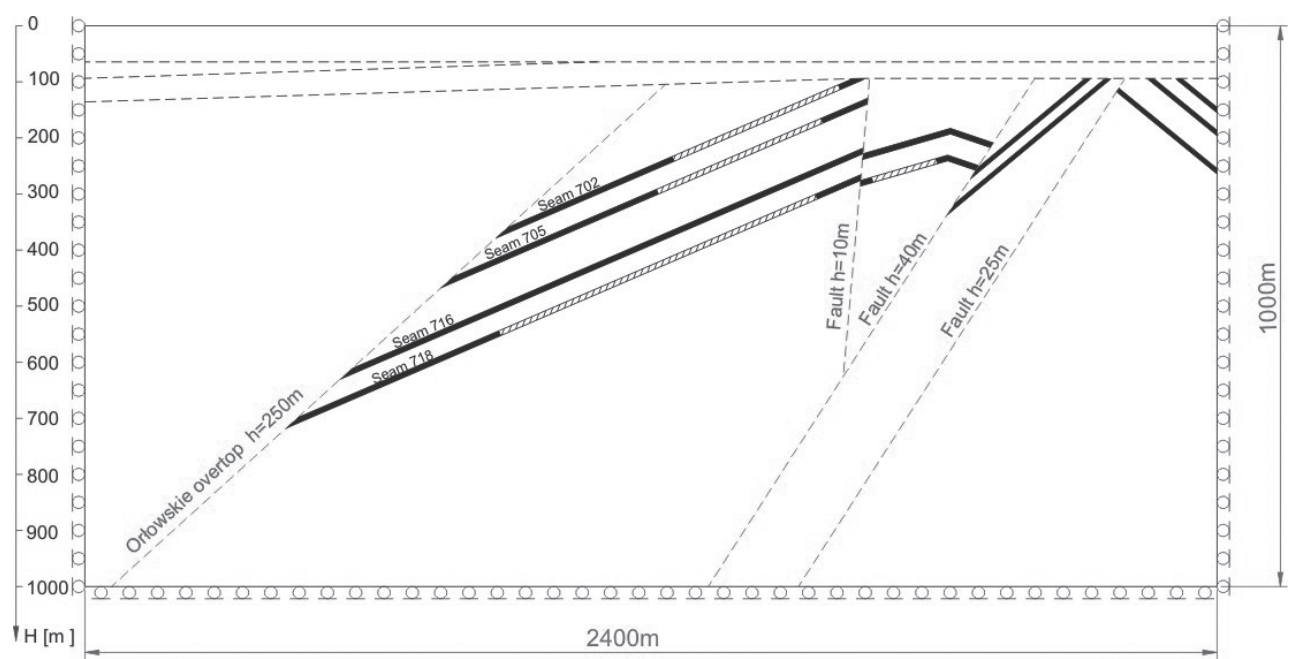

Fig. 1. Schematics of calculation model.

extraction. Layer 716 has not been mined. In the mining area the layers' inclination changes in the range of $24-28^{\circ}$. In order to simplify the building of the numerical model, it was assumed that the inclination of the mined layers is constant and amounts to $26^{\circ}$. Roof and bottom layers have been presented on the basis of the profile from shaft I from SRK S.A. KWK Makoszowy area. Fig. 1 shows the schematics of the rock mass and the locations of faults.

Considering multiple tectonic dislocations, the rock mass model has been divided into three parts:

- The left part of the model along with Ormowskie overlap is presumed to be the mining area in layers 702,705 , and 718 .

- The central part of the rock mass in the shape of a wedge restricted by faults with $10 \mathrm{~m}$ and $40 \mathrm{~m}$ slips is presumed to be a mining area in layer 718

- The right part of the model between the $40 \mathrm{~m}$ slip fault and right boundary of the model is presumed to be the area where mining did not occur. In this part, another fault is presented with a $25 \mathrm{~m}$ slip.

In a mathematical sense it has been assumed that

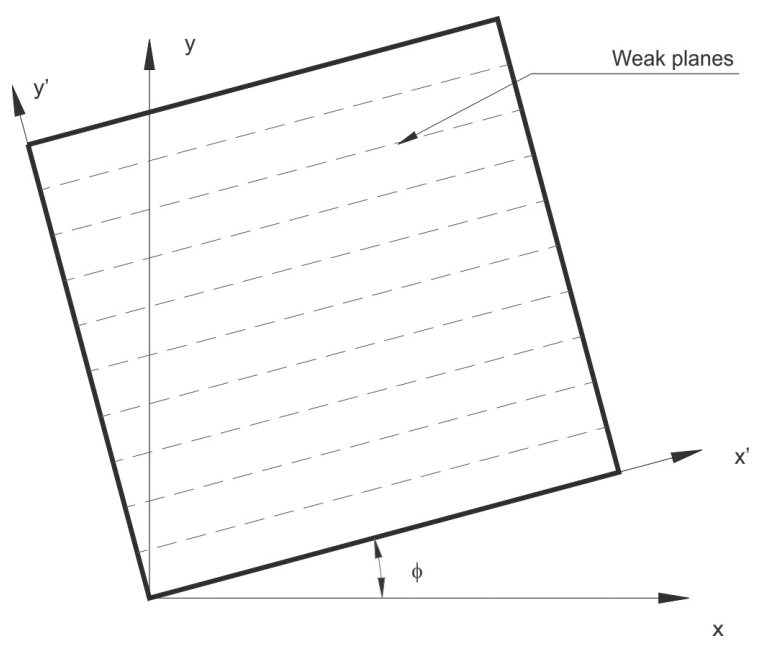

Fig. 2. Ubiquitous joint medium. all the layers building the rock mass model have been described by ubiquitous joint medium (Fig. 2). The model is the anisotropic plasticity model, which includes weak planes in specified orientation (Mohr-Coulomb yield (plasticity) criterion). Yielding can occur both within weak planes and rock mass. Isotropy planes and weak planes can be inclined at any $\alpha$ angle to $X$ axis.

Strength parameters and layer deformation have been selected based on mining data and literature [7-8]. The situation described in the study has been used to specify the values of weak plane parameters [9]. The range of variability of rock layer material parameters for our ubiquitous joint model, which was used for calculations, is presented in Table 1 .

The simulation of coal layers' exploitation relies on the removal of respective zones located in the area of goafs. Simultaneously between top and bottom layers, contact elements have been introduced to prevent interweaving of the top and bottom of the modeled seam. This mining simulation method eliminates the necessity to use additional parameters bound to collapse zones. Simulation of rock mass displacement matches the quasistatic model, where the impact of exploitation (removal) of another element is instantly noticeable. There is a lack of viscous elements and there is no concept of time. However, considering that the medium has plastic characteristics, the sequence of exploitation (removal) of respective zones of the grid is highly significant.

In the modeling process, the working space of the mining face as well as its supports have not been included, considering their negligible effect on rock mass deformation. The height of the fall above the longwall face has been designated based on numerical simulation that included the range of uplifting of top and bottom layer rocks.

All the layers specified in the model are separate parts connected to each other via contacting planes. Structural schematics and the mechanical model of a contact plane are presented in Fig. 3. The model consists of two opposite sides: $A$ and $B$. Respective parts of the contact plane are 
Table 1. Layer parameters for ubiquitous joint model selected for calculations.

\begin{tabular}{|c|c|c|c|c|c|}
\hline & Unit & Overburden & Shale & Sandstone & Coal layer \\
\hline \multicolumn{6}{|c|}{ Rock mass parameters } \\
\hline Shear modulus G & $\mathrm{MPa}$ & 114 & 2,680 & 4,350 & 864 \\
\hline Bulk modulus K & $\mathrm{MPa}$ & 247 & 2,630 & 4,760 & 1,830 \\
\hline Cohesion c & $\mathrm{MPa}$ & 0.46 & 10.7 & 20.75 & 6.26 \\
\hline Internal friction angle $\phi$ & Degrees & 24 & 24 & 35 & 25 \\
\hline Tensile strength $\mathrm{Rr}$ & $\mathrm{MPa}$ & 0.1 & 5.25 & 9.50 & 1.6 \\
\hline Volumetric density $\rho$ & $\mathrm{kg} / \mathrm{m}^{3}$ & 1,950 & 2610 & 2450 & 1,400 \\
\hline \multicolumn{6}{|c|}{ Weak planes parameters } \\
\hline Cohesion c & $\mathrm{MPa}$ & 0.0046 & 0.1 & 0.2 & 0.06 \\
\hline Internal friction angle $\phi$ & Degrees & 24 & 24 & 24 & 24 \\
\hline Tensile strength $\mathrm{Rr}$ & $\mathrm{MPa}$ & 0.001 & 0.05 & 0.1 & 0.01 \\
\hline Volumetric density $\alpha$ & Degrees & 0 & $4(8 *)$ & $4\left(8^{*}\right)$ & $4\left(8^{*}\right)$ \\
\hline
\end{tabular}

*Value of plane inclination angles in inter-fault zone

connected by normal spring stiffness $(K n)$ and tangent stiffness $(K s)$ with elements $S$ and $T$, which represent shear strength and tensile strength limits. Utilizing such connections allows for the simulation of interlayer slips and the simulation of cavity formation between the interacting layers of the model [10-12].

In the initial conditions (primary stress state) between interacting sides of the contact there is opening resistance and friction. These forces disappear the moment the separation of layers takes place. The size of the fracture opening between interacting layers is constantly controlled by software. Further closing of the fractures restores only friction in the model. Based on Fig. 3, assigning junction points to each of the contact layers independently results in deformations in specific layer being reliant only on the assigned deformation parameters.

Values of the parameters for contact planes that define interlayer contacts are presented in Table 2 [13]. These parameters have been selected by the author based on
Table 2. Mechanical parameters of interlayer connections selected for calculations [13].

\begin{tabular}{|c|c|c|}
\hline Parameter & Unit & Value \\
\hline Normal stiffness coefficient $\left(\mathrm{K}_{\mathrm{n}}\right)$ & $\mathrm{MPa} / \mathrm{m}$ & 50 \\
\hline Tangent stiffness coefficient $\left(\mathrm{K}_{\mathrm{s}}\right)$ & $\mathrm{MPa} / \mathrm{m}$ & 20 \\
\hline Friction angle $(\phi)$ & Degrees & 28 \\
\hline Consistency $(\mathrm{c})$ & $\mathrm{MPa}$ & 0.9 \\
\hline Tensile strength $\left(\sigma_{\mathrm{T}}\right)$ & $\mathrm{MPa}$ & 0.001 \\
\hline
\end{tabular}

initial computer simulations. Their goal was to properly adjust the model horizontal displacements to the values, which were designated in situ.

Faults have been represented as two interacting planes connected by analogical contact elements as in the case of interlayer connections. This is a big simplification as

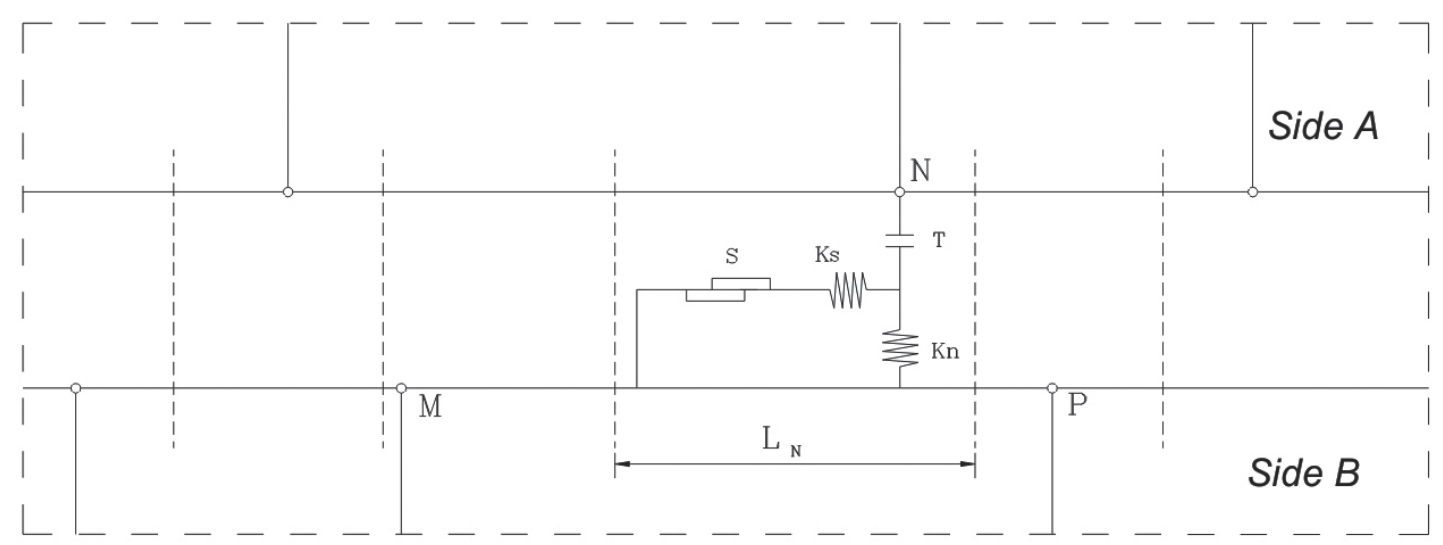

Fig. 3. Schematics of separation plane. 
Table 3. Fault mechanical parameters selected for calculations.

\begin{tabular}{|c|c|c|}
\hline Parameter & Unit & Value \\
\hline Normal stiffness coefficient $\left(\mathrm{K}_{\mathrm{n}}\right)$ & $\mathrm{MPa} / \mathrm{m}$ & 120 \\
\hline Tangent stiffness coefficient $\left(\mathrm{K}_{\mathrm{s}}\right)$ & $\mathrm{MPa} / \mathrm{m}$ & 45 \\
\hline Friction angle $(\phi)$ & degrees & 28 \\
\hline Consistency $(\mathrm{c})$ & $\mathrm{MPa}$ & 0.4 \\
\hline Tensile strength $\left(\sigma_{\mathrm{T}}\right)$ & $\mathrm{MPa}$ & 0 \\
\hline
\end{tabular}

it leads to the omission of the secondary fault zone that is often present in the area of big tectonic dislocations. Table 3 presents the values of material constants that specify mechanical characteristics of fault fractures. Considering the lack of data in regards to properties of the material that fills the fault fractures, the values of parameters characterizing the fault have been selected based on literature.

The presented model has been described using a differential grid. This way the surface has been divided into zones with shapes resembling rectangles [14-18]. Considering the lack of data about tectonic residual stress, it is assumed that the value of primary stress in the rock mass comes only from gravitational forces [19]. Primary horizontal stress $\sigma_{x}$ has been designated by the means of initial numerical calculations.

\section{Results}

The simulation of mining exploitation has been conducted based on the rock mass model presented above. It consisted of three stages:

- Representation of primary stress with consideration of existing tectonic dislocation.

- Nullification of dislocations in the model with preservation of existing stress conditions.

- Selection of exploitation fields for longwalls 702, 705, and 718 in the model; this part of the simulation of mining has been conducted as part of a multistage calculation process.

- Presentation of changes created as a result of flooding of goafs.

\section{Subsidence trough Formed After Completion of Exploitation in Seams 702, 705, and 718}

After simulation the primary stress conditions in the modeled rock mass and the creation of a so-called null model, the simulation of mining in seam 209/1 started. This stage of computer simulation was done in order to present the influence of mining in longwalls 702,702 , and 718 on surrounding rock mass and the designation of "high fall" above these faces.

Due to insufficient data related to the order of mining operations and their quarterly advances, the simulation of mining in the coal seams mentioned above has been conducted within a single calculation cycle. Based on the results it can be stated that:

1. On the surface, mining resulted in the formation of a subsidence trough with the highest value of subsidence of around $2.30 \mathrm{~m}$ (Fig. 4). Considering this was a multi-seam exploitation with controlled collapse into the goafs, the maximum value of terrain subsidence obtained through computer simulation is relatively small. When evaluating the shape of subsidence trough profile it should be noted that there is noticeable asymmetry of influence between edges where mining started and edges where it stopped. This is a result of inclination of the exploited seam and activation of fault planes. The factor that seems to have especially high significance when it comes to the shape of the profile of subsidence trough is the presence of the fault in the place where mining started in seams 702, 705, and 718. In the inter-fault part, the additional exploitation in seam 718 caused more subsidence on the model surface. However, the value of this subsidence does not exceed $0.2 \mathrm{~m}$. Also, works of A. Kowalski et al. [20] and R. Ścigała [21] mention that additional subsidence might occur in the near-fault areas.

2. Similarly, to subsidence, the horizontal deformations are clearly asymmetrical (Fig. 5), which is a result of influence of the direction of mining and activation of fault plane in the area of the starting edge of exploitation in respective seams. Extreme values of positive horizontal deformation near the starting edge of the faces are bigger than the deformations near the edge that ends the exploitation. Similar asymmetry of ground surface deformation occurring in areas of beginning and ending of mine operations was also predicted by J. Białek [22]. In the area where mining starts, the maximum value of positive deformations is $4.10 \mathrm{~mm} / \mathrm{m}$, while near the ending edge analogical values of positive deformations are $0.55 \mathrm{~mm} / \mathrm{m}$ respectively. The extreme value of negative deformations is $-2.14 \mathrm{~mm} / \mathrm{m}$. The course of horizontal deformations and their high value $(4.14 \mathrm{~mm} / \mathrm{m})$ confirms the fact of activation of the fault plane. Opening these planes causes significant change of horizontal deformations in the fault's outcrop and slight shift of extreme values of deformation in the direction of a selected exploitation field. A local change in the number sign of the deformation's value may be a cause of deformations in the form of surface fractures. The calculated increase of the horizontal deformations bears surge characteristics that include only a small area of the overburden layer. Simultaneously, activation of fault planes caused a slight restriction of the range of horizontal deformation.

3. The numerical calculations for the completed exploitation stage shows that the maximum inclination of the surface locally reaches $16.4 \mathrm{~mm} / \mathrm{m}$ and is present above the overlaying goafs in 702 and 705 layers, and 
$x[\mathrm{~m}]$

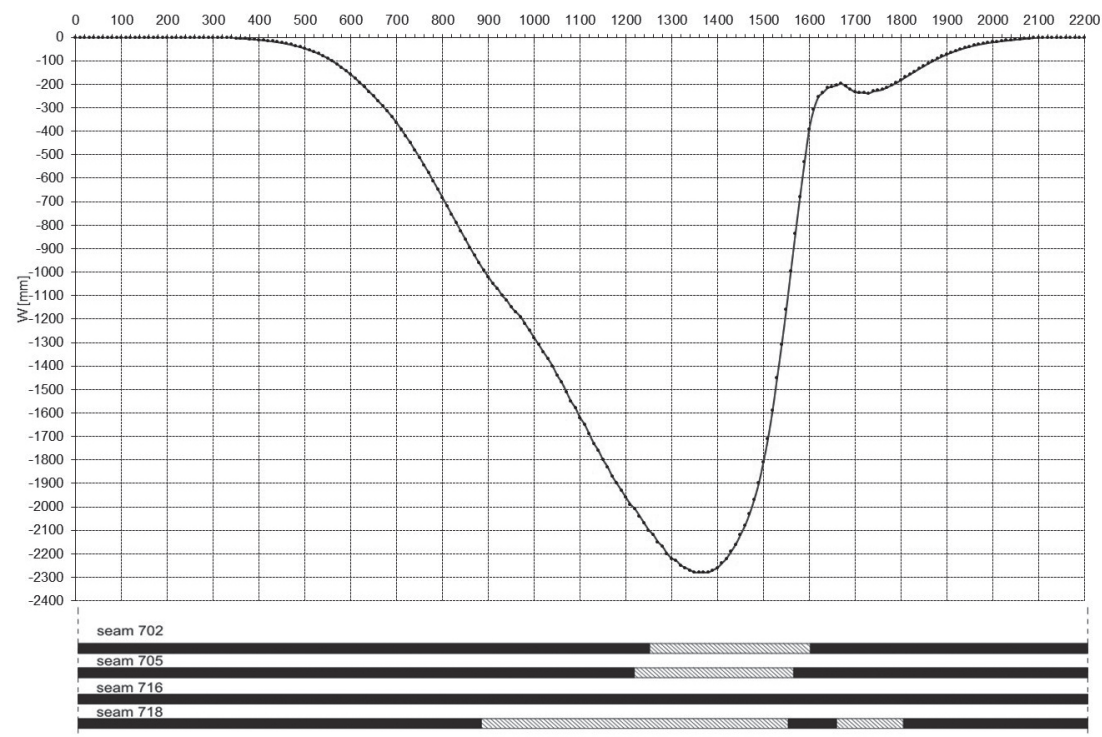

Fig. 4. The subsidence trough was formed after completion of exploitation in seams 702,705 , and 718 .

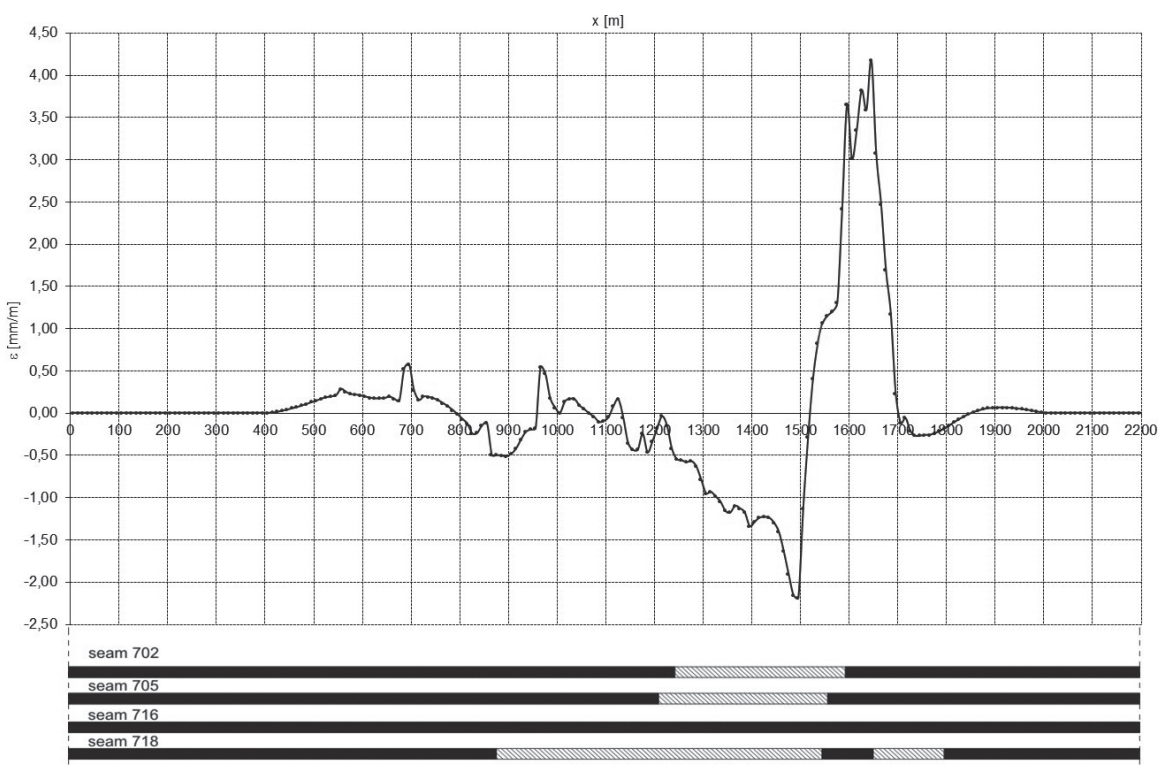

Fig. 5. Horizontal deformations after exploitation in seams 702, 705, and 718.

partially above the selected part of layer 718 (Fig. 6). In the remaining part of the model inclination does not exceed $4 \mathrm{~mm} / \mathrm{m}$. Such distribution of inclination is related to a difference in mining conditions (longwall lengths) during the formation of a basin's slopes. The results for completed mining exploitation show that the maximum surface inclination values allow us to classify the area as category $\mathrm{V}$ of mining areas.

Table 4 presents a compilation of deformation indicators designated after completing the exploitation in layers 702, 705, and 718 .

4. The mining extraction in seams 702,705 , and 718 resulted in a vast model of rock structure damage (yielding of grid zones). The greatest damage is present in the zone where exploitation fields overlapped each other in respective seams. In this area the damage includes a significant portion of overburdening rock mass that occasionally reaches the surface. According

Table 4. Deformation indicators designated after completing exploitation in layers 702,705 , and 718 .

\begin{tabular}{|c|c|c|}
\hline Deformation indicators & Unit & Value \\
\hline Maximum subsidence $\mathrm{W}_{\max }$ & $\mathrm{mm}$ & +33.9 \\
\hline Maximum inclination $\mathrm{T}_{\max }$ & $\mathrm{mm} / \mathrm{m}$ & 0.17 \\
\hline Tensional deformation $\varepsilon^{+}$ & $\mathrm{mm} / \mathrm{m}$ & 0.08 \\
\hline Compressional deformation $\varepsilon^{-}$ & $\mathrm{mm} / \mathrm{m}$ & -0.08 \\
\hline
\end{tabular}




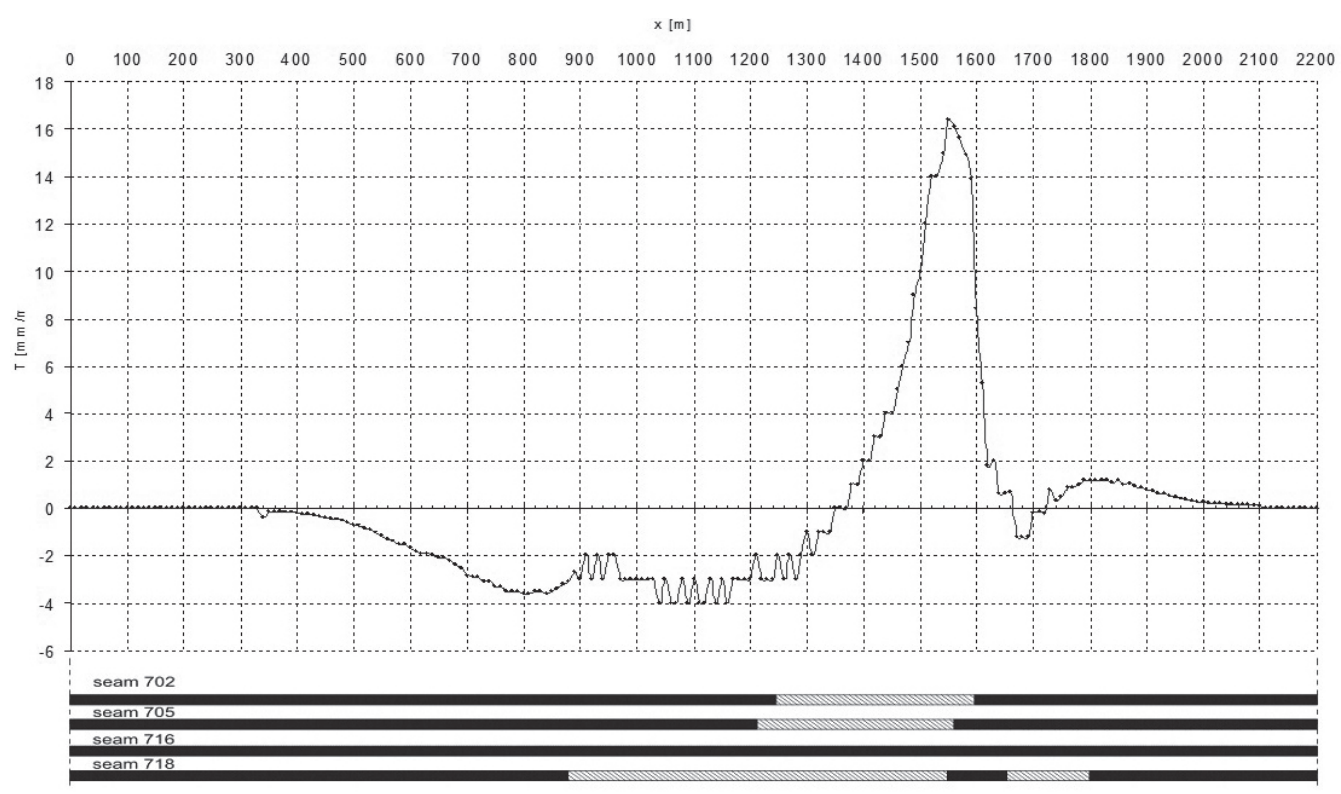

Fig. 6. Inclination of the surface after exploitation of layers 702, 705, and 718.

to Fig. 7, the characteristics of damage show that the damage covers mainly the weak planes of ubiquitous joint medium. The range of yield zones is much higher in the area where mining has begun (fault area) as a result of the interaction of both mining area edges, which disappears as mining proceeds. Analysis of changes occurring in the rock mass after completion of mining works also exceeded the assumed consistency of fault planes and the small opening of fault planes in the model.

\section{Discussion}

Another stage of conducted numerical calculations was the evaluation of influence of flooding of goafs on the mining area surface. For this purpose, the elements, which were located in the damage zone presented in Fig. 6, were assigned the pressure increase resulting from the height of mining water level. The analysis of hydrostatic pressure formation in the rock mass with $\mathrm{t}$ he phreatic zone established at $+240 \mathrm{~m}$ above sea level shows that this pressure in relation to selected exploitation parcels may change in the range of $1.4 \mathrm{MPa}$ to

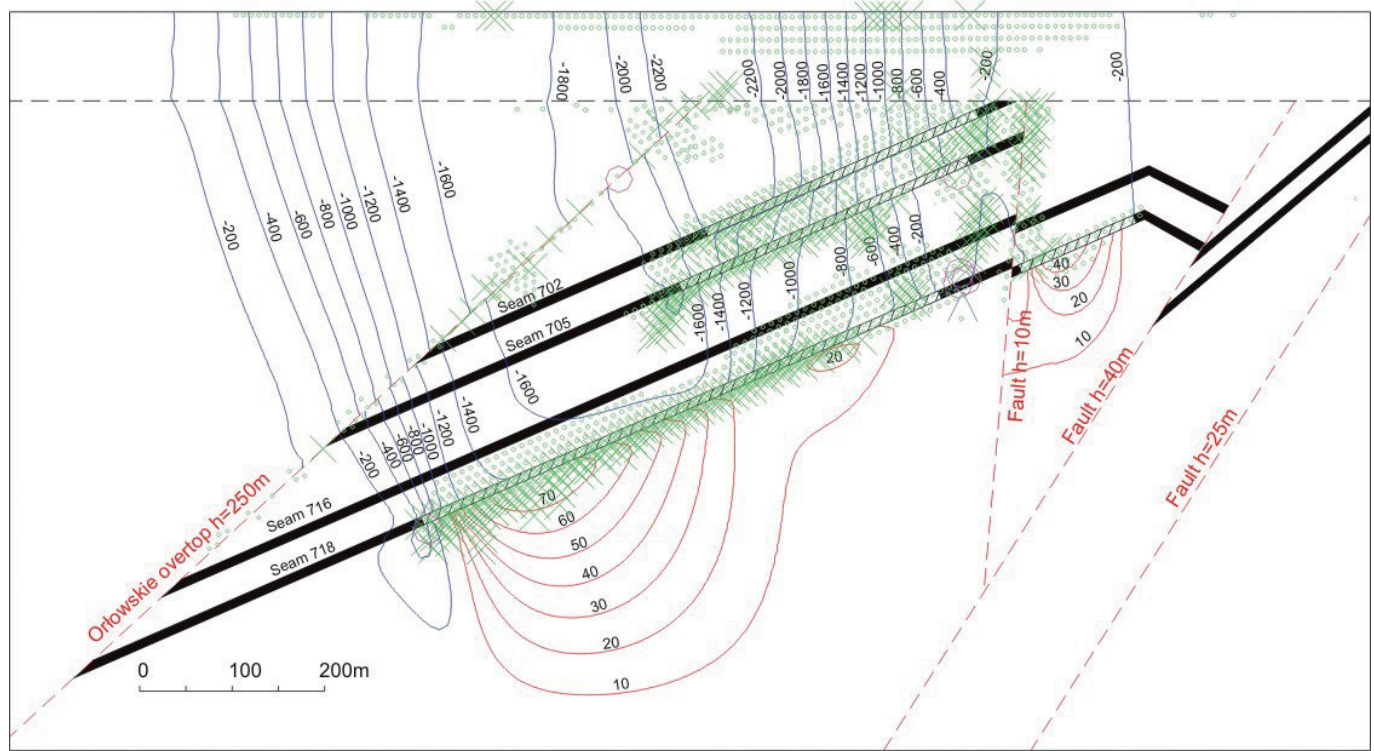

Plasticity Indicator:

* at yield in shear or vol., X elastic, at yield in past, o at yield in tension, o ubiq. joints fail in past,

$\wedge$ slip along ubiq. Joints, $v$ tens fail. ubiq joints.

Fig. 7. Subsidence and yield zones in the model, formed after exploitation of seams 702, 705, and 718 ended. 
4.0 MPa. For a phreatic zone like this, the whole calculation cycle has been done, which allows us to state the following:

1. The flooding of goafs in 702,705 , and 718 with the phreatic zone established at $+240 \mathrm{~m}$ above sea level cause a relative uplift of the surface in the model by about $34 \mathrm{~mm}$ (Fig. 8). The highest value of the uplift has been designated in the location of overlapping of exploitation fields of every seam. In comparison to the maximum subsidence designated after the exploitation, the uplifts are relatively small and do not exceed $2 \%$. In the remaining portion of the model the uplift of the surface should not exceed $6 \mathrm{~mm}$. As indicated by Maj [23], these uplifts were induced by an elastic mechanical reaction resulting from an increase of pressure acting on the walls of voids, growing proportionally to the water lever and buoyancy effect.

2. Flooding of goafs causes changes in terms of horizontal deformations of the surface model. However, these are small and do not exceed $\pm 0.08 \mathrm{~mm} / \mathrm{m}$ (Fig. 9). In comparison to the previous stage of computer simulation (deformations designated after mining ended), extreme values of secondary deformations are relatively small and do not exceed $2 \%$ for positive deformations and $4 \%$ for negative deformations.

3. The inclination values determined after flooding of goafs in 702,705 , and 718 are relatively small and do not exceed $0.2 \mathrm{~mm} / \mathrm{m}$. Places of maximum inclination occurrence are analogical to the first stage of computer simulations and are related to the edges of goafs in

$x[m]$

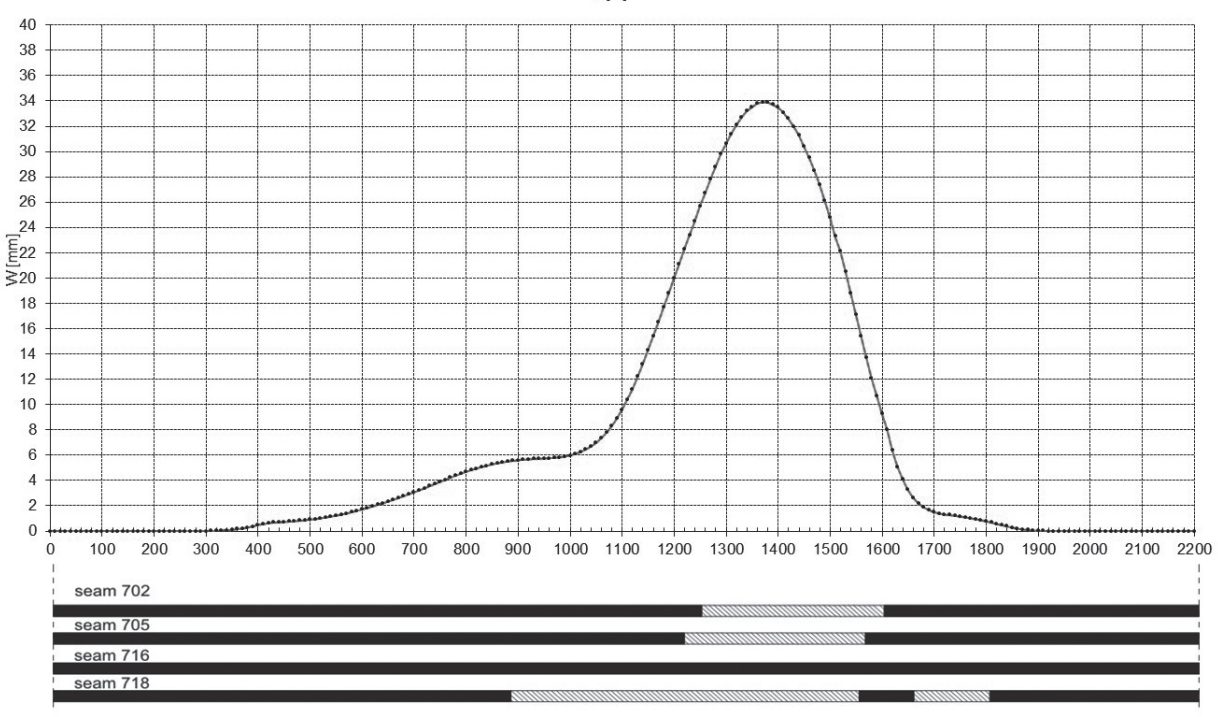

Fig. 8. Predicted surface uplifts after flooding of goafs in seams 702, 705, and 718.

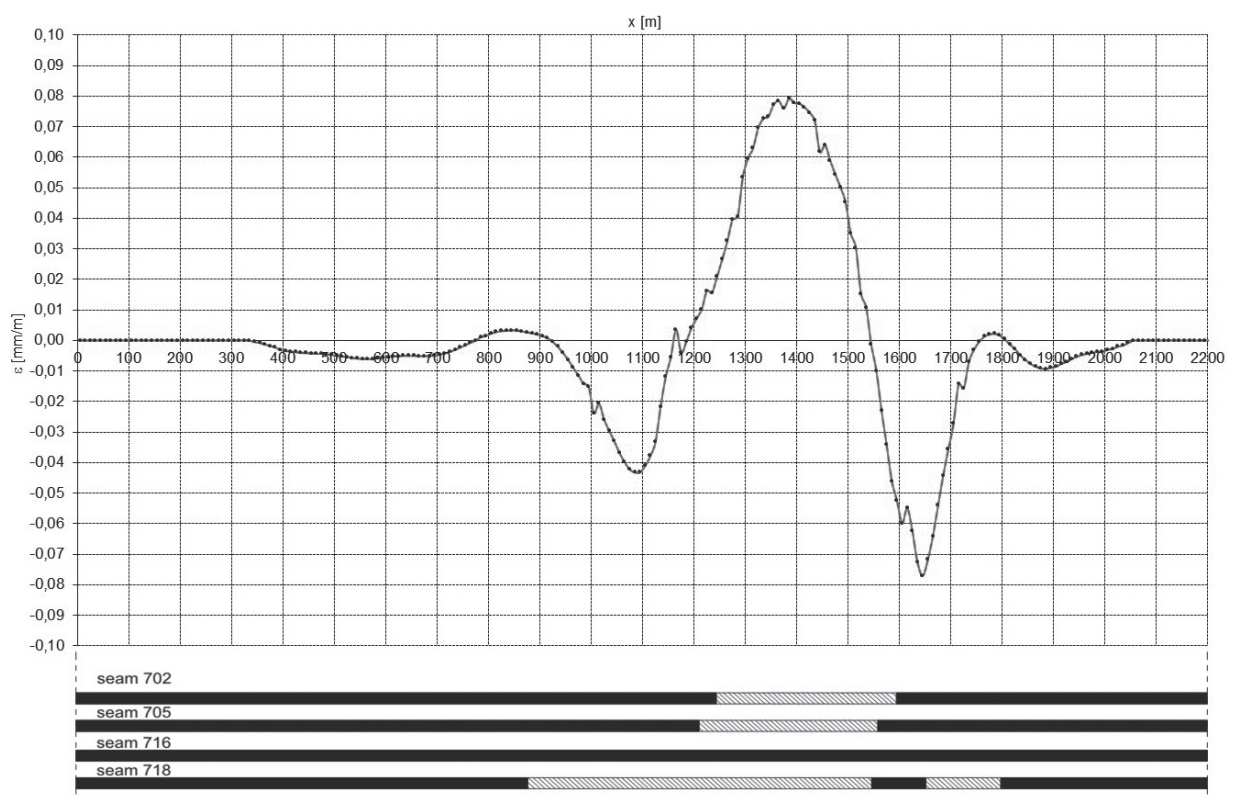

Fig. 9. Predicted horizontal deformations after flooding of goafs in seams 702, 705, and 718. 


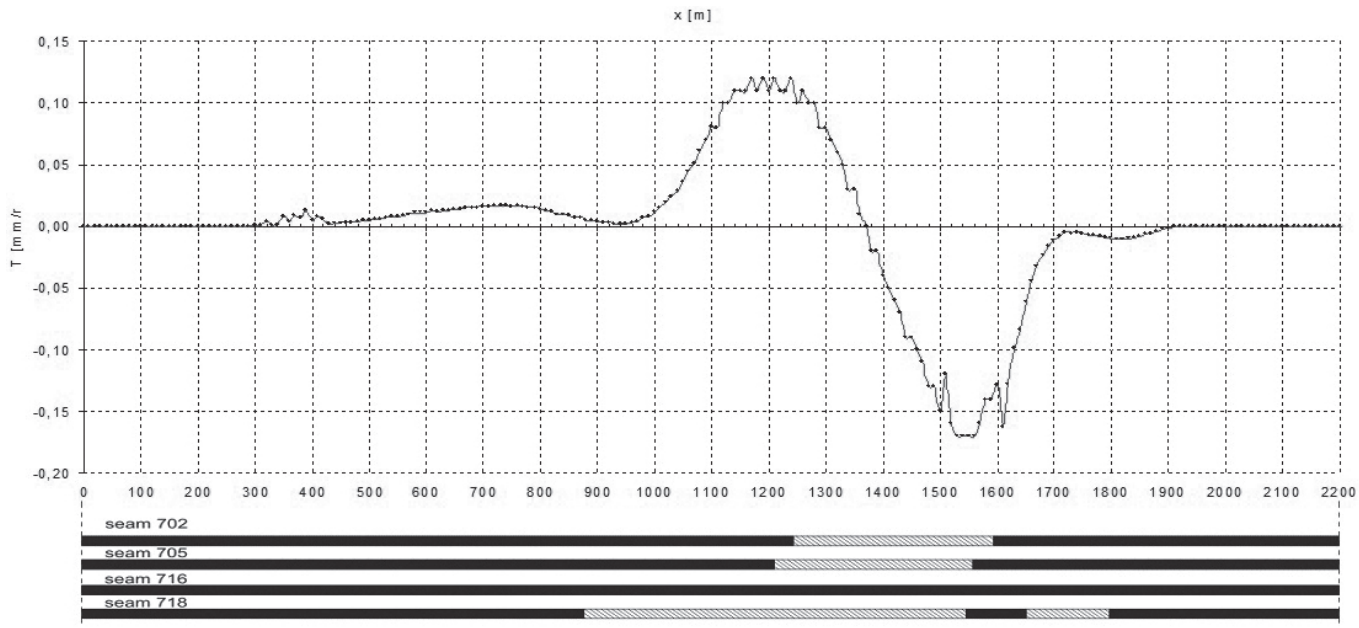

Fig. 10. Inclinations after flooding of goafs in layers 702, 705, and 718.

702, 705, and 718. Changes in surface inclination determined after flooding of goafs are presented in Fig. 10.

4. The conducted simulation showed that flooding of goafs in 702,705 , and 718 will not cause significant changes to the yielding zones in comparison to the stage designated after mining ended. The disturbed consistency of fault planes in the previous calculation stage allows for free movement triggered by the flooding of cavings. Fig. 11 presents the distribution of the damage zones (yielding) formed after flooding. Table 5 compiles surface deformation indicators determined after flooding of goafs in 702, 705, and 718 .

The problem with the influence of mining operations on the ground surface after their completion has so far been considered only in the area of their appearance until
Table 5. Deformation indicators determined after flooding of goafs in layers 702, 705, and 718 .

\begin{tabular}{|c|c|c|}
\hline Deformation indicators & Unit & Value \\
\hline Maximum subsidence $\mathrm{W}_{\max }$ & $\mathrm{mm}$ & +33.9 \\
\hline Maximum inclination $\mathrm{T}_{\max }$ & $\mathrm{mm} / \mathrm{m}$ & 0.17 \\
\hline Tensional deformation $\varepsilon^{+}$ & $\mathrm{mm} / \mathrm{m}$ & 0.08 \\
\hline Compressional deformation $\varepsilon^{-}$ & $\mathrm{mm} / \mathrm{m}$ & -0.08 \\
\hline
\end{tabular}

complete termination of the ground and disappearance subsequent motions of the surface. Although the whole time of deformation process of the rock mass resulted from conducted mining operations usually amounts to 2-3 years,

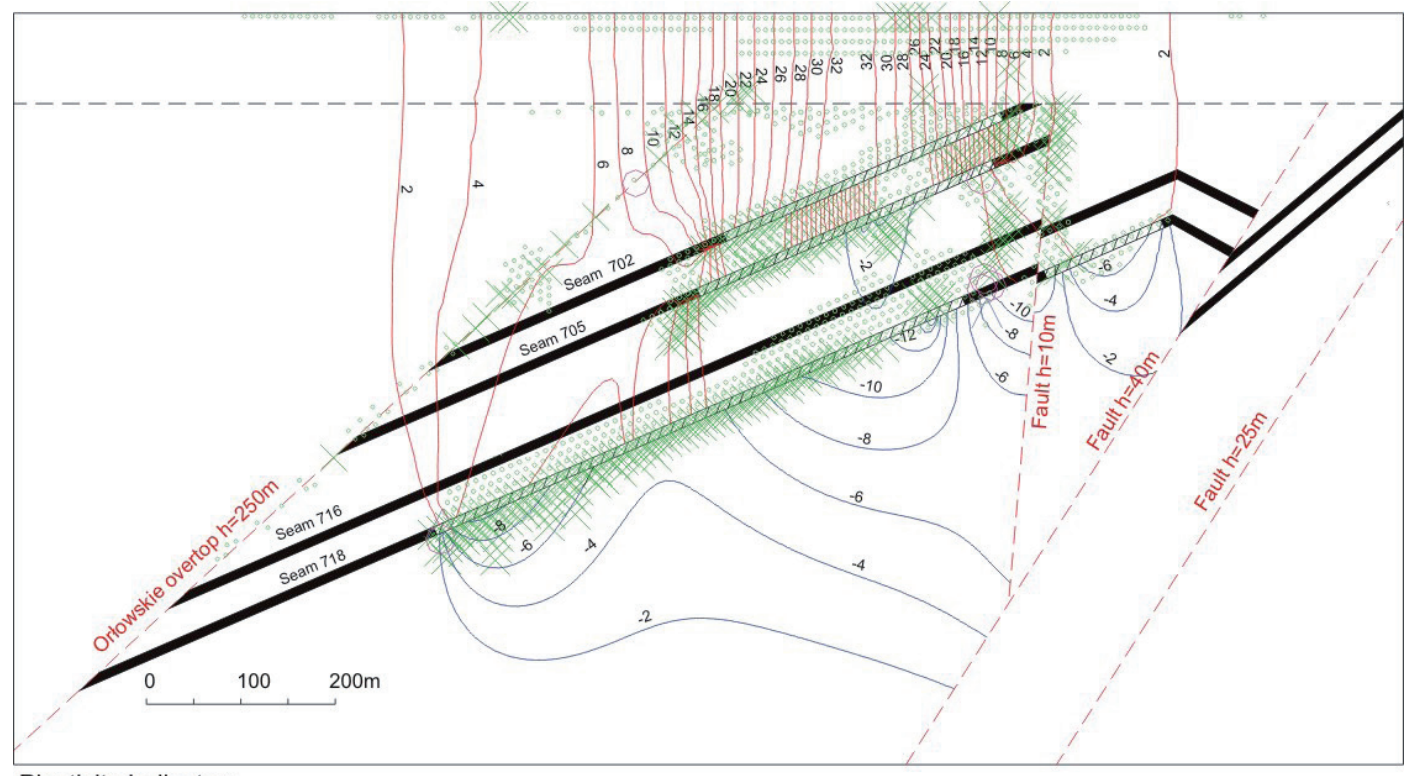

Plasticity Indicator:

* at yield in shear or vol., X elastic, at yield in past, o at yield in tension, o ubiq. joints fail in past,

$\wedge$ slip along ubiq. Joints, $v$ tens fail. ubiq joints.

Fig. 11. Subsidence and yield zones in the model, formed after flooding of goafs in seams 702, 705, and 718. 
the terminal phase is not completely defined. Regarding dependence on the depth of mining and properties of rocks, which form the rock mass, the vanishing ground subsidence phase lasts until an imaginary boundary, where two measurements conducted within the interval of one month exhibit subsidence smaller than, i.e., $1 \mathrm{~cm}$ or $1 \%$ of the subsidence that already appeared. After this timespan, the surface of the ground is considered as stabilized and free from deformations resulting from conducted mining extraction, thus no further survey of such areas has been continued in terms of ground movements. For this reason there is a lack of information about the behaviour of the rock mass for a long time after the completion of mining. However, the situation changes when areas of ceased mining become flooded due to the restoration of original water relations or intentional use of cavings as a water reservoir. Observations conducted in the Netherlands and Germany showed that secondary watering of the rock mass may induce measurable, significant vertical movement of uplifting grounds. Shocks of the rock mass are also probable, which can be initiated by these movements, or displacement of rock layers along fault planes supported by watering of the rock mass. Currently in Poland no observations of these phenomena have occurred.

\section{Conclusions}

This article shows the results of numerical modeling of possible surface uplift predicting caused by mine flooding, and the results of calculations of their possible size. For the purpose of calculations the model was used based on ubiquitous joint medium. Based on obtained numerical results, the following conclusions can be made:

1) The conducted analysis showed that the use of numerical modeling of the rock mass provides the possibility of predicting uplifts of a surface caused by flooding of goafs. This can lead to the occurrence of adverse effects on surface objects.

2) The pressure of water filling the goafs is an important factor in size uplifting.

3) Based on the results of computer simulation, we noted that the maximum value of the uplifting in the considered area amounts to around $34 \mathrm{~mm}$. This value does not exceed $2 \%$ of the subsidence caused by primary exploitation. The highest value has been designated in the area of an exploitation field overlapping respective seams.

4) Flooding of goafs also causes changes in terms of horizontal changes to the surface model. These changes are small and do not exceed $0.1 \mathrm{~mm} / \mathrm{m}$.

\section{Acknowledgements}

The presented article was based on the commissioned analysis and evaluation of the possibility of developing post-mining areas for the construction of a planned motorway.

\section{References}

1. PÖTTGENS J.J.E. Soil uplift and groundwater rise from geotechnical and maritime geodetic View in the AachenLimburg coalfield. Freiberg research books A 847, mining and geotechnics, 193, Freiberg. 1998.

2. FENK J. An analytical solution for calculating elevation the surface of the day with flooding of underground mine plant. The Mine Survey 107, 2000.

3. FENK J. Analityczne rozwiązanie opisujące wypiętrzenie powierzchni występujące przy likwidacji kopalń przez zatopienie (Analytical solution of ground surface uplift occurring by the flooding of liquidated mines). Mining Review. Przegląd Górniczy 11/1999 r. [In Polish].

4. MAJCHERCZYK T., NIEDBALSKI Z., KOWALSKI M.: 3D numerical modeling of road tunnel stability - the laliki project. Archives of Mining Sciences. 57 (1), 61, 2012.

5. SROKA A. Przyczynek do prognostycznego obliczania ruchów pionowych powierzchni terenu spowodowanych wzrostem poziomu wód kopalnianych (A contribution to calculation of vertical movement of the surface caused by increase of mine water levels). Materiały Szkoły Eksploatacji Podziemnej. 2006 [In Polish].

6. FLAC User's Manual. Itasca Consulting Group. Minneapolis. 2011.

7. MAS IVARS D., PIERCE M.E., DARCEL C., REYESMONTES J., POTYONDY D.O., YOUNG R. P., CUNDALL P.A. The Synthetic Rock Mass Approach for Jointed Rock Mass Modelling, International Journal of Rock Mechanics and Mining Sciences , 48, 219, 2011.

8. YANG S.Q., HUANG Y.H., JING H.W., LIU X.R. Discrete element modeling on fracture coalescence behavior of red sandstone containing two unparallel fissures under uniaxial compression. Engineering Geology. 178, 28, 2014.

9. SAINSBURY B., PIERCE M., MAS IVARS D.: Simulation of rock mass strength anisotropy and scale effects using a ubiquitous joint rock mass (UJRM) model. Continuum and Distinct Element Numerical Modeling in Geo-Engineering, Detournay \& Cundall (eds.) Paper: 06-02 Itasca Consulting Group, Inc., Minneapolis. 2008.

10. BAHAADDINI M., SHARROCK G., HEBBLEWHITEA B.K.: Numerical investigation of the effect of joint geometrical parameters on the mechanical properties of a non-persistent jointed rock mass under uniaxial compression. Computers and Geotechnics. 49, 206, 2013.

11. BLACHOWSKI J., ELLEFMO S. Numerical modelling of rock mass deformation in sublevel caving mining system. Acta Geodynamica et Geomaterialia, 9 (3), 379, 2012.

12. WESOŁOWSKI M. The possibilities of using anisotropic models of rock mass to describe deformations of the mining area surface. Archives of Mining Sciences. 61 (1), 125, 2016.

13. DRZEWIECKI J. Wpływ parametrów uskoku na zasięg jego oddziaływania (Influence of the parameters of the fault on the range of its influence. Mining and Geoengineering, Book 2. 2011). Górnictwo i Geoinżynieria, Zeszyt 2. 2011 [In Polish].

14. KWAŚNIEWSKI M., LASEK S. Numerical Analysis of methane migration from floor strata to a longwall face. Journal of Coal Science and Engineering No 2, 


\section{9.}

15. HARTHONG B., SCHOLTÈS L., DONZÉ F.V. Strength characterization of rock masses, using a coupled DEMDFN model. Geophys Journal International. 191 (2), 467, 2012.

16. NURIC A., NURIC S., KRICAK L., LAPANDIC I., HUSAGIC R. Numerical Modeling and Computer Simulation of Ground Movement Above Underground Mine. International Journal of Environmental, Chemical, Ecological, Geological and Geophysical Engineering 6 (9), 2012.

17. KOŁODZIEJCZYK K. Numerical Simulations of Polydispersed Suspension Sedimentation in Ansys CFX. Pol. J. Environ. Stud. 23 (3), 1003, 2014.

18. LISJAK A., GRASSELLI G. A review of discrete modeling techniques for fracturing processes in discontinuous rock masses. Journal of Rock Mechanics and Geotechnical Engineering. 6 (4), 301, 2014.

19. STRZAŁKOWSKI P., TOMICZEK K. Analytical and numerical method assessing the risk of sinkholes formation in mining areas. International Journal of Mining Science and Technology. 25 (1), 2015.

20. KOWALSKI A., JĘDRZEJEC E., GRUCHLIK P. Linear discontinuous deformations of the surface in the Upper Silesian coal basin. Archives of Mining Sciences, 55 (1), 2010.

21. ŚCIGAŁA R. Wpływ tektoniki złoża na rozkład deformacji terenu górniczego (Effect of bed tectonics on the deformation of mining area. Silesian University of Technology). Wydawnictwo Politechniki Śląskiej, Gliwice. 2013 [In Polish].

22. BIAŁEK J. Prognoza kategorii odkształceń poziomych wykonana $\mathrm{z}$ założonym poziomem jej bezpieczeństwa (Prognosis of horizontal strains categories with an assumed level of safety. Mining Review). Przegląd Górniczy 8/2013 [In Polish].

23. MAJ A., KORTAS G., DROGOWSKI J. Ground uplift after the closure of water leak on Mina drift of the Wieliczka Salt Mine, Geology, Geophysics \& Environment 38 (1), 2012. 